\title{
Censors
}

\section{At work, censors out of work}

\section{Louise Williams}

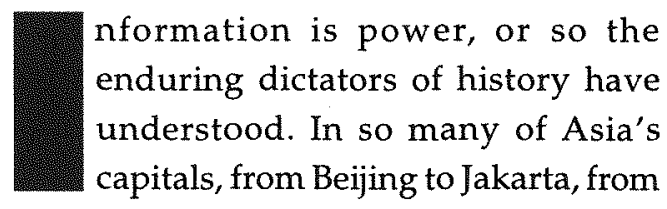

Rangoon to Hanoi, the scene was the same. In obscure back rooms, rows of desks lay lined up, their surfaces rubbed smooth by years of diligent effort, as the faceless agents of authoritarian states dutifully poured over newspapers and magazines. Carefully, the swarms of censors cut out 'subversive' articles from abroad, one by one, or bent low over 'offensive' captions and photographs and blacked them out by hand. They laboured over their own local newspapers too, erasing hints of rebellion and allusions to unpalatable truths tucked within the reams of propaganda. The carefully edited articles that resulted were read by one and all, but believed by very few.

The authoritarian, or quasi-authoritarian regimes of the post-colonial era in Asia, understood well the relationship between control over information and political power. In China, reading groups are convened to vet the ideological content of newspapers and to sway appropriately with the prevailing political winds. In Burma and Vietnam regimes still prefer risking the death of artistic expression by subjecting even song lyrics to the dour committees of ideological correctness. In the not-too-distant past, the enemy governments of South and North Korea, faced each other across the de-militarised zone, their regimes carrying labels from the opposite sides of the ideological spectrum, but their authoritarian controls over information much the same. And in Soeharto's Indonesia the military intelligence service worked directly within parts of the local media as well as harassing, cajoling and co-opting the foreign press. 
The political leaders of hundreds of millions of people took a personal, almost petty interest in their own propaganda. To the Chairman, the Great Leader or Secretary Number One, even obscurely critical references in minor publications were enough to attract their attention, and spark offence. So concerned were they about the moulding of their own images as great statesmen that the line between ego and political control sometimes blurred. Thus it was in Indonesia that former authoritarian leader, Soeharto, raged over the slight to his family implied by the Sydney Morning Herald's decision to breach the unspoken taboo and publish details of their personal wealth. And so it was, and in some places still is, that senior politicians spent their late evenings personally checking editions of daily newspapers before they went to print.

In North Korea citizens are subjected to the ultimate insult; the state security apparatus bans them from locking their doors at night so intelligence officials can wander in at will to ensure no unauthorised reading, listening or discussing is going on inside. Singapore has almost completed the electronic version of the same controls-a nationwide, government-run communications network which will bring the Internet into every home, and just as conveniently allow the authorities to wander into the cyberspace to check up on its citizens at any time.

In Malaysia and Singapore a western-style press flourished in form, but not in content. A sophisticated combination of legislation and ownership concentration ensured the media remained under control. In nations wracked by periods of acute political instability, like Thailand, the Philippines, and Cambodia, the messengers themselves sometimes became the victims-murder serving as the ultimate sanction against freedom of the press.

Control of the media has served as an integral part of maintaining political control in many authoritarian nations around the world. Whether claiming legitimacy from the political left or the political right, nondemocratic regimes all agreed to control the flow of information to their people. Communist regimes had a finely honed system of control inherited from Lenin and Stalin and perfected over decades in the Soviet Union. The right-wing generals who ruled much of the balance were quick to learn the tricks of the censor's trade. So uniform was the model of political power in Asia during the economic boom of the 1980s, that a new 'Asian' model was widely discussed-one in which individual rights were 
curtailed in the name of stability and individuality was submerged in favour of the economic progress that, it was argued, unfettered leadership could deliver. Within that model of authority, control of the press was essential.

Now the political map of the region is shifting, with control over the press and the technology of information dissemination never before so important in determining who will hold the reins of power. Losing control of information is one crucial factor in losing political control. Prodemocracy movements, assisted by the underground press, the Internet, and even mobile phones, have swept away authoritarian governments in Indonesia, Thailand, the Philippines, South Korea, Taiwan and even Mongolia in the past 15 years.

The new Wahid Goverment in Indonesia has simply abandoned control altogether, announcing the abolition of the Department of Information, where all those faceless bureaucrats at rows of wooden desks had wielded so much power under former President Soeharto. With a simple announcement the censors were no more. Among the new bureaucratic structures, a new Department of Human Rights would be established instead.

It would be simple if the debate over freedom of the press stopped there-with a black and white battle between the censors and the proponents of free speech. But there are many other issues to confront. Are the region's remaining censors fighting a futile battle against satellite television and the Internet, or could a compact, sophisticated, affluent state such as Singapore, wrest control over the next generation of information technology? And when the censors lose, does freedom of the press necessarily follow?

Here we learn that when the state relinquishes control of information a power vacuum is left behind. Into that vacuum rush a whole range of vested interests as new power structures are shaped. Can businesses or politicians just as effectively capture the press through the free market, using simple outright ownership or more underhand methods such as bribery?

The much-vaunted free market itself is a far from perfect model for the media. In a truly free market will not sensationalism win the day as the consumers' taste for scandals, violence and gore inevitably pulls the media away from serious news reporting? 
Without the censors who will control the press in their new role as society's self appointed watchdogs? In the newly democratising nations of Asia, where civil society and its institutions such as Press Councils and professional bodies to police press ethics are in their infancy, it is both fair and relevant to ask 'who will watch the watchdogs?'

\section{Information technology as friend and foe}

From South Korea to Indonesia, authoritarian regimes attempted to combine free market economics with closed political systems, which included significant controls over the flow of information. Many nations were successful in the short term, recording significant economic growth which, in itself, discouraged the millions who had gained material wealth from rocking the political boat.

The most rapid industrialisation in the history of the world was occurring in East Asia. Despite the label 'economic miracle', fast growth created urgent new social problems such as a yawning gap between the new rich and the old poor, mind-numbing pollution, the destruction of urban and rural communities to make way for development and massive migration flows towards the factories. The face of East Asia was being transformed.

Rapid economic growth in East Asia was kindled by large, cheap labour markets. The tiger economies and their aspiring cubs realised, however, that both technology and capital were essential to take the next leap in economic development beyond the cheap clothing factories and 'dirty' industries. Information technology was at the cutting edge of that leap, as was integration into global financial systems. Both brought with them unwelcome bedfellows.

It can be argued that new information technology so seriously undercut the ability of governments to control information, in nations such as Indonesia and Thailand, that the fall of authoritarian regimes was inevitable. Just as information is power, so too is technology. The spectacular advances in communications and information technology, the advent of satellite television and the globalisation of the media made the old-time censors, with their quaint armoury of scissors and thick, black pens, obsolete. New battle lines are being drawn for control of the Internet and the airwaves, but the speed of transmission and the volume of 
information flashing its way around the world means this is a much more difficult line to hold.

It seems the dilemma now facing East Asia's remaining authoritarian regimes is how to balance the need for technology for economic development against the risk of losing control of information and, in turn, losing political control. The hermit states of North Korea and Burma seem to have decided to forfeit technology altogether, choosing autarky, and condemning their people to grinding poverty, to maintain tried and true models of information control.

China, Vietnam, Malaysia and Singapore, on the other hand, are seeking ever-more sophisticated means of information control, erecting electronic 'firewalls' to control Internet providers or even building the entire information network themselves. But, pressures continue to build in the region for greater press freedoms. The integration of once closed or isolated economies into the world economy has brought new demands for transparency, openness and the functioning of civil society. There is a clear need for scrutiny and criticism of the political tools of power and there are ever louder calls for an end to tools of repression such as censorship and the imprisonment, or worse, of dissidents.

So the autocrats are fighting a war on two difficult fronts. They have to face demands for democracy and the rule of law from their own people and from the international community while at the same time fighting to retain the tools of repression, including controls over information flows. Advances in information technology constantly move the bar higher.

It starts with pencil and paper. In the late 1960s, as Soeharto consolidated his hold on power, more than ten thousand Indonesian 'leftists', many of them writers and artists, were rounded up and shipped off to Buru island. So isolated was this barren, windswept piece of land that the island itself was a sufficient prison. Included among the survivors was Indonesia's best known author, Pramoedya Ananta Toer, who was held on Buru for more than ten years. There, he says, inmates were beaten if they were found with any reading material or caught with a paper, pens or pencils.

In Ceasescu's Romania every typewriter in the country was registered to ensure that dissident views could not be printed or published. In Burma today, every fax machine must be registered with the authorities to ensure that contact with the outside world is always vetted by the generals. In the Philippines it was photocopying machines which assisted the samizdat 
(or 'guerrilla press') in publishing alternative newspapers exposing the Marcos regime. In Thailand it was the VCR which allowed people to view illegal, pirated tapes copied from foreign satellite television broadcasts of the massacre of pro-democracy demonstrators by soldiers in Bangkok.

From the early 1990 s mobile phones became important political tools, allowing organisers to pull together protest rallies in Jakarta, or disperse them in the face of a crack down. That tool carried pro-democracy movements one step beyond the illegal radio broadcasts which had called Filipinos into the streets in the mid 1980s.

Today it is the Internet. In Indonesia, the Internet was widely used to distribute articles critical of the Soeharto regime and to organise mass protests. Beijing's ongoing rage against the Falun Gong is being insidiously countered by thousands of quiet emails and caustic chat comments.

The Communist Party of China recognises that without information technology it cannot fuel its economic ambitions and thus continue to deliver even modest economic growth. And without growth it cannot hope to maintain stability and political power. Yet that very technology includes the Internet, allowing overseas Chinese pro-democracy groups to launch daily attacks on the regime across the telephone wires, opening and closing their web pages in a single 24 hour period to avoid detection. The Chinese Government can, and does, control Internet providers in China. It can, and does, impose harsh penalties on those caught accessing dissident material. But, the race to keep up with the Internet is a far more arduous task than maintaining control over conventional newspapers.

In Laos, the government-controlled Vientiane Times suddenly appeared in an illegal Internet addition, launched from outside the country, its usually tame columns complemented by a readers' section filled with critical comments. The 'guerrilla' Internet edition was condemned in the pages of the local newspaper, a move which only attracted more attention to the rebel edition without stopping the perpetrators.

In Burma and North Korea, progress is simply passing the people bythus avoiding, or at least delaying, the collapse of tragically archaic systems of government with their systems of information control. These regimes have chosen isolation over economic development-and so the censors' scissors still wield power because the Internet is banned and few have the technology or the knowledge necessary to use it anyway. 
It seems oddly incongruous that so backward a nation as Burma sits smugly besides Singapore, one of the most technologically advanced nations on earth. The Burmese generals prefer simply to keep their heads in the sand, while Singapore is intent on building the world's most elaborate sandcastle. All eyes must now turn to Singapore where the government is building the entire communications network itself-known as Singapore One. By next year every household in the island nation will be 'online', linked into a national electronic network offering sophisticated communications options and the Internet in every home. But, with ownership and control of the technology, can the government also effectively 'spy' on its citizens merely by downloading personal emails, or monitoring what people are reading on the Internet? Filters can be installed blocking out pornography, for example, as well as politically sensitive material.

It can be argued that Singapore is an exception to the rule-as a tiny nation more like a medium-sized city it can be much more easily managed (or controlled) than the vast reaches of China, for example. But Singapore, particularly founding leader Lee Kuan Yew, has played an important role in the 'Asian values' debate of the 1980s, and may play an important role in demonstrating the outer limits of control of new information technology in the new millennium.

For decades Singapore has fascinated political observers with its apparently contradictory mix of free market capitalism and political controls-Asia's big brother/or big father' society was making it out there in the freewheeling international marketplace. Lee Kuan Yew argued that curbing western-style freedoms, such as freedom of speech and freedom of the press, met a 'higher' goal of social stability which, in turn, paved the way for rapid economic development. Thus, a government had the moral right to curtail an individual's freedoms in exchange for economic rights.

It is not surprising that Vietnam has already sent teams to Singapore to study 'firewalls' to be built into the Internet and other tactics for information control. In Vietnam attempts are being made to train officials of the security apparatus to chase electronic information across the Internet, and to limit use of global information networks by making them expensive and accessible only through government agencies. 


\section{May the market forces be with you}

There is a divide emerging between regimes clinging to authoritarian political models and the region's new young democracies. This gulf is also reflected in attitudes towards the press. The range of attitudes span the totalitarian control of all information in Pyongyang, the use of information as propaganda in Beijing or Hanoi, the retention of the form but not the reality of a free press in Malaysia and Singapore and the 'wild west' freedom of the press in the Philippines. The problems of the press in Indonesia, Thailand and the Philippines are in many ways the most worrisome. The laws are largely in place but the result leaves much to be desired. Simply sacking the censor is not sufficient. In these countries, true freedom of the press is a distant ideal, not a reality. Censorship has been replaced by an uncomfortable form of information anarchy in the new democracies.

Once state control is relinquished a much more complicated power struggle is unleashed for control over the media. First cab off the rank is the simple commercial interest of private media companies seeking profits through sensationalism. Then there is the power of advertisers to influence editorial content by threatening to remove their accounts. Next come the politicians and business people who can take control by gaining ownership of newspapers or radio or TV stations themselves. Finally, there is the threat of bribery of journalists by vested interest groups and, if that doesn't work, there is the threat of violence against journalists by the old power holders such as the military.

Ironically, in a number of East Asia's young democracies, freedom of the press has unleashed the forces of sensationalism and voyeurism in such extreme forms that they are challenging cultural norms and community standards. With freedom comes the right to sell newspapers using bikini girls and horrific, intrusive photographs of terrible accidents. With freedom comes the right to use local movie stars as newsreaders and choose to lead the news bulletin with gossip about show business figures.

So serious is the drift towards the 'tabloidisation' of the media in Hong Kong, that a local group felt the need to set up a 'pollution index' to try to monitor sleaze, fabrication and scandals. The driving force behind tabloid journalism is simply profit; demonstrating that with the free market comes 
the right to disseminate any kind of information, including pornography, violence and gore. Market forces are ultimately amoral.

The price of press freedom in the short term has been information anarchy, with the free market the new bottom line. The free market, however, does not take into account ethics or values, nor does it necessarily reject biases based on commercial interests, nor demand the media play a public service role by providing high quality, independent news and analysis.

The problem, too, with an entirely private, commercial media is that profits will continue to be the driving force behind television programming. Can an entirely private media serve the public honestly? Without independent, government or publicly funded broadcasters, such as the BBC, Australia's ABC, PBS in the United States, or Germany's Deutcshe Welle, it is difficult to imagine where high quality current affairs and news programs will come from.

It is possible, however, that global news services, such as CNN and the BBC World Service, may be able to influence local demand for quality current affairs because they are now being beamed into Asia via satellite. This helps explain the fascination of the authoritarian states with the Ted Turners of this world. They recognise raw power when they see it. Pyongyang was fascinated that a fellow pariah state, Iraq, had been able to tell its side of the story to the world on CNN. Beijing continues to dangle the prize of a billion viewers in front of a fascinated Rupert Murdoch. Autocrats have the choice of banning CNN or courting it. They cannot ignore it. So global news may have its positive side. It might be guilty of simplification, trivialisation and, at times, obfuscation, but it will not risk its global audience by allowing itself to be the vehicle for a one-party state's national propaganda.

In a truly free market there are no gatekeepers, only consumers. In a number of countries important debates are underway on how to impose controls which deal with issues of values, taste and respect for privacy without allowing governments to use the issue of media quality as an excuse to return to government controls.

Already, tentative moves are being made in Thailand and Hong Kong to create Press Council type bodies to protect the public from the excesses of tabloid journalism and industry bodies to produce self-regulatory 
guidelines for the media. But with heavy-handed censorship such a recent memory in Thailand, and with fears of intervention in the media by Beijing in Hong Kong, these are sensitive debates indeed.

In Thailand and Japan in 1999, landmark freedom of information legislation was introduced, opening up government departments to scrutiny by the public and the press. Thailand's Prime Minister Chuan Leekpai put the matter simply and eloquently: 'the public should know what the government knows'. This is the debate the newly democratic countries of East Asia must engage in. They are debating the limits of the market as a regulator and the need for legal and professional institutions to act as a brake on the excesses to which the market will otherwise lead.

\section{Reporting corruption, corrupt reporting}

A free press is not a luxury. A free press is at the absolute core of equitable development, because if you cannot enfranchise poor people, if they do not have a right to expression, if there is no searchlight on corruption and inequitable practices, you cannot build the public consensus needed to bring about change (James Wolfensohn, International Herald Tribune, 11 November 1999).

The conspiracy of silence on corruption is over. Wolfensohn is right to put reporting about corruption at centre stage. Reporting corruption can also be used as a gauge to test the degree of freedom the press is being allowed. In totalitarian societies, the leadership can do no wrong so the reporter is committing the crime in reporting corruption. The Burmese generals won't even allow consumer complaints about businesses run by their families or friends. The more progressive Chinese and Vietnamese leaders value the role the press can play in investigating and reporting official corruption. As such they have begun to incorporate a role for the state-controlled media in corruption investigations, adding a veneer of accountability to their own regimes. But they nevertheless insist on the final say in what will be printed and who will be shielded from the press. Only middle-level bureaucrats are lined up and sentenced to death on government television in China, serving as an example to others. Journalists who misunderstand this reality can themselves be jailed. The question is whether regimes such as China can manage to finesse the issue of the reporting of corruption to use it to enhance their own credibility. 
Corruption by strongmen and their cronies has been the dominant theme of Asia's pro-democracy movements. Former Philippines strongman, Ferdinand Marcos, and his counterpart in Indonesia, Soeharto, were visibly seen to have amassed vast fortunes for their families by abusing their political power. At every level authoritarian regimes boasted a raft of officials who did just the same; the nature of the political power structure facilitated corruption because there were no watchdogs to hold the power élite to account. At an every day level, on the street corners where police braved the thick fumes and the tropical heat, in the queues for driving licences, and in the offices where applications for school places were shuffled, the example from the leadership was followed. Corruption was part of the system and no one was allowed to complain lest the finger be directed at the billionaire president.

Overlaying any discussion of press reporting on corruption is both the legacy of the recent past and dominant cultural mores. Investigative reporting is a skill much in demand but little evident. In the new democracies, analysts have pointed to the problem of a free press being run by a generation of journalists trained under government controls. Journalists now face the task of making sense of the new political power map and the complex social and economic changes industrialisation has brought, often without the necessary analytical or research skills. A number of media commentators have pointed to an inadequate understanding of press ethics, such as the Indonesian tabloid which proudly and unselfconsciously calls itself Trial by the Press. In Mongolia, the flagship communist mouthpiece modelled on Pravda tried to lure back readers by changing its name from Truth, to the more provocative Is It True?

The reskilling of journalists is a challenge. The culture of fact-checking needs to be instilled in an entire generation of journalists accustomed to being told what to report. This problem goes well beyond the communist states of East Asia. Early indications in Thailand suggest few reporters are seeking the previously classified documents under the new Freedom of Information Act. So accustomed are journalists to simply being 'handed' information to publish that the majority have remained in the comfort zone of the past, merely waiting for news to be leaked through highly politicised channels instead of taking the initiative themselves.

The information comfort zone must also include culture. In Japan, East Asia's first industrialised nation with a long history of democratic 
processes and freedom of the press, what the public is offered is strongly influenced by the long-standing practice of herd journalism. In Japan, a sophisticated system of information management has been established which pulls journalists together into press clubs, known as kisha clubs. These clubs are attached to political parties, chambers of commerce and even business groups, where the same information is provided to all. The warmth of the herd discourages individual initiative and the cosy press clubs this system is built around have their own subtle censorship codessuch as the denial of further cooperation with journalists who break from the pack.

How a free press will report corruption remains a crucial issue. It is already apparent that information about corruption can be used as a political tool. Just as political camps leak details of the corrupt practices of their opponents in the west, and the media is used in a political power play, so too will a free press be used in Asia.

At the same time self-censorship continues. In Hong Kong, journalists fearful of the implications of the return to the former British colony to China have steered clear of sensitive subjects despite no direct intervention from Beijing. Right across the board self-censorship is determined by the personal experiences of journalists; those raised with the fears of censure of the past must be more reticent despite recent changes. South Korea's press is still recovering from the wounds of the strongman's controls. Indonesia's journalists are delighted but stunned by the abolition of the Department of Information. After more than three decades of intimidation, direct controls, harassment and co-option, reporting taboos have been built in to the media's psyche. It takes more than overnight political change to build a new media.

Many journalists in East Asia's new democracies are poorly paid and equally poorly trained. They find it difficult to operate effectively within a free press environment. In a number of countries, including the Philippines, Thailand, Indonesia and South Korea, there is an ongoing culture of 'envelope journalism' despite the reforms of the political system. Bribes paid directly to journalists have long been used to influence editorial content, and this kind of corruption is rationalised as not morally wrong but simply a part of the system and an expected bonus for journalists.

Corruption within the media is potentially a very serious problem, given the dominant role the press is playing now in reporting on corruption 
within governments in young democracies. When authoritarian governments controlled the press the public was unable to gain access to information about the corrupt practices of officials. With a free press, however, corruption at all levels can be reported, including corruption of the media industry itself.

'Envelope journalism' is perhaps the greatest threat to the credibility of a free press. It cannot be justified by reference to the poverty of the journalist in question. In Australia, the two most highly paid radio journalists in the country insisted on being paid millions more from business for favourable editorial comments about those business' products. The 'cash for comments' scandal in Australia is merely the end point that envelope journalism reaches.

\section{The endgame is democracy}

'When people look back at what happened in this century, they will find it difficult not to accord primacy to the emergence of democracy as the preeminently acceptable form of governance' (Sen 1999:4). This was Nobel laureate Amartya Sen's response to the question of what was the most important thing to have happened the 20th century. 'This recognition of democracy as a universally relevant system, which moves in the direction of its acceptance as a universal value, is a major revolution in thinking, and one of the main contributions of the twentieth century.'

Democracy made its way in East Asia in the last years of the last decade of the century. There are the examples of Japan, Taiwan and South Korea in Northeast Asia, and the Philippines and Thailand in Southeast Asia. The entire international community is keeping its fingers crossed that Indonesia can also make the transition. Successful transition to democracy with multi-party elections and liberal values is now seen as the key to good governance and sustainable economic development.

The decisive battle for democratisation is the fight for freedom of the press. The flow of information is the key to empowering people. The most powerful weapon in the battle for democracy is the truth and it is the media that is charged with delivering it as best it can to the people. This is a fact that autocrats understand even better than democrats. So the issue of freedom of the press takes on the broadest dimensions. It is not just a battle to ensure respect for Article 19 of the Universal Declaration of 
Human Rights. It is a battle to determine the shape of society, its mores and the functioning of its political system.

Losing Control: freedom of the press in Asia takes us right up to the end of this tumultuous century. It deals with the Chinese media cranking up its latest propaganda campaign, this time against the Falun Gong. It discusses how the Indonesian media lost its way in reporting the tragedy in East Timor. And it comments on how the Cambodian media-or at least parts of it-surprisingly reported the allegations that the Prime Minister's wife had her husband's movie star girlfriend assassinated.

The book adopts a country-by-country approach dealing with all the countries in Northeast and Southeast Asia. It does not attempt to sweep across to the sub-continent. It would not be possible to do justice to any discussion of freedom of the press in that region by sandwiching it in between the pages of a book about East Asia.

The methodology is based on an underlying assumption: that journalists are best placed to provide the most up-to-date analysis of their own industry. Where possible, local journalists have contributed the country chapters. In some cases a more useful outcome could be achieved by employing foreign correspondents and commentators. Authors have written their chapters using journalistic research tools, such as first hand interviews, as well as more conventional academic methods.

Willy Lam, one of the most respected journalists writing on China, gives us insight into the thought processes of the decision-makers in China and explains how they are trying to handle the dilemma of dealing with information flows. Walter Hamilton puts his years in Japan to good use in explaining the difficulty of breaking free of the herd mentality. Kavi Chongkittavorn traces the development of Thai democracy and the press freedoms which now accompany it from the perspective of one who has participated in that struggle.

Andreas Harsono lives through his chapter on Indonesia, a journalist both exhilirated and concerned over the speed and direction of events. And in Sheila Coronel's chapter on the Philippines one can discern both pride in the country's achievement in democracy and exasperation at how it is being used.

Peter Mares and Roger du Mars explain the situation in Vietnam and South Korea respectively by analysing their histories. Both nations have 
difficult pasts which point to problems in their present handling of media issues. Mary Yang and Dennis Engbarth trace the path by which Taiwan could boast perhaps the freest media in Asia.

Chris Yeung devotes considerable attention to the handover of Hong Kong to China and the shadow Beijing will cast in the future.

It has been left to Krzysztof Darewicz and my co-editor Roland Rich to deal with the difficult totalitarian end of the press freedom spectrum in North Korea and Burma. Roland Rich nevertheless finds a few rays of light in Cambodia and Mongolia.

Amando Doronila provides his perspective in an insightful essay on a complex issue, one which he has long faced as a prominent journalist and editor both in the good years and the bad. He is the doyen of Asian journalists and his voice needs to be heard.

All the contributors attacked their subjects individually but many have taken up similar themes and issues and it is on these and the many examples provided in the book that this overview chapter has drawn. 